\title{
To treat or not to treat: HER2 equivocal is the matter!
}

\author{
Armando Orlandi ${ }^{1}$, Vincenzo Arena ${ }^{2}$ \\ ${ }^{1}$ Department of Medical Oncology, ${ }^{2}$ Department of Laboratory and Diagnostic Medicine, Fondazione Policlinico Universitario “A. Gemelli”, Rome \\ 00168 , Italy \\ Correspondence to: Armando Orlandi, MD, PhD. Department of Medical Oncology, Fondazione Policlinico Universitario “A. Gemelli”, Rome 00168, \\ Italy. Email: armando.orlandi@policlinicogemelli.it.
}

\begin{abstract}
With the introduction of the 2013 American Society of Clinical Oncology (ASCO)/College of American Pathologists (CAP) guidelines for human epidermal growth factor receptor type 2 (HER2) testing, some authors noticed an increase in equivocal HER2 determinations. Indeed, many retrospective assessments showed an increase of up to $14 \%$ in the number of equivocal cases by immunohistochemistry and fluorescence in situ hybridization. In these cases, if after reflex testing with the same and/or an alternative specimen the HER2 test result is deemed to be equivocal, the ASCO/CAP guidelines recommend to consider HER2-targeted therapy. However, due to the absence of prospective data on the efficacy of anti-HER2 therapy in equivocal HER2 breast cancer (BC), the therapeutic decision is extremely complex, especially in the adjuvant and neoadjuvant settings. In this perspective paper, we analyse the available retrospective data aiming to answer to the dilemma whether to treat or not to treat HER2 equivocal cases with a HER2-targeted therapy.
\end{abstract}

Keywords: Human epidermal growth factor receptor type 2 (HER2); equivocal; American Society of Clinical Oncology/College of American Pathologists (ASCO/CAP); target therapy

Submitted Jun 30, 2017. Accepted for publication Aug 15, 2017.

doi: $10.21037 /$ tcr.2017.08.34

View this article at: http://dx.doi.org/10.21037/tcr.2017.08.34

Human epidermal growth factor receptor type 2 (HER2) is overexpressed in about $15 \%$ to $20 \%$ of invasive breast cancers (BCs) and is related with modest clinical outcome $(1,2)$. In the adjuvant setting prospective and randomized clinical trials involving trastuzumab (the first humanized monoclonal antibody that binds HER2) plus chemotherapy showed approximately a $50 \%$ reduction in risk of recurrence and an improvement of overall survival in HER2-positive BC patients (3-6). Even in the metastatic setting, the introduction of several anti-HER2 treatments significantly improved the prognosis of HER2-positive BC patients (7-9). Given these evidences, HER2 status determination for newly diagnosed invasive BCs is now mandatory in order to select the best treatment (10). After the introduction into clinical practice of trastuzumab, it quickly became evident that HER2 test was subject to important discrepancy between laboratories, leading to divergent results in up to $20 \%$ of cases (11). Therefore, in 2007, the American Society of Clinical Oncology (ASCO) and the College of American Pathologists (CAP) panel developed guidelines to enhance the precision of HER2 testing in BC (12). Regardless of significant accent on advance made to standardize HER2 test after promulgation of the ASCO/CAP guidelines in 2007, many reports persist to demonstrate absence of concordance for interlaboratory HER2 results (13). Since then, clarifications and updates to these guidelines have been released and in 2013 the ASCO/CAP conducted a formal and comprehensive review (14). In this version, the authors change the immunohistochemical features to assess HER2 protein overexpression, keeping the classification into two major groups: HER2-positive (score 3+) and HER2-negative (score 0 and $1+$ ). In case of equivocal HER2 expression (score 2+), HER2 positivity must be validated by fluorescence in situ hybridization (FISH). Using FISH, HER2 positivity is defined by a HER2 gene copy number $\geq 6$ or a HER 2 gene to chromosome 17 (HER2/CEP17) 
ratio $\geq 2.0$, while HER2 negativity is considered in case of a HER 2 copy number $<4$ and a HER2/CEP17 ratio <2. BCs with a HER 2 copy number of 4-6 and a HER2/CEP17 ratio $<2$ are defined as HER2 equivocal. Moreover, the authors state that "if the HER2 test result is ultimately deemed to be equivocal, even after reflex testing with an alternative assay, the oncologist may consider HER2-targeted therapy".

With the introduction of the 2013 ASCO/CAP guidelines, some authors noticed an increase in equivocal HER2 determinations (15-18). Indeed, many retrospective assessments published in the last years showed an increase of up to $14 \%$ in the number of equivocal cases (15). Moreover, our institutional experience matches with these observations. The absence of prospective data on the efficacy of anti-HER2 therapy in equivocal HER2 BCs and the consequent omission of clear recommendations by the ASCO/CAP, make the therapeutic decision extremely complex, especially in the adjuvant and neoadjuvant settings. Waiting for the results of the NSABP-B47 trial, that will assess the impact in terms of invasive disease-free survival (IDFS) of the addition of trastuzumab to chemotherapy in patients with low expression of HER2, we should base our therapeutical choice on retrospective evidences.

Recently, Criscitiello et al. retrospectively analyzed 455 consecutive early BC patients with a HER2 score $2+$ and a HER2/CEP17 ratio <2.0 and reported no significant link between recurrence risk and HER2 equivocal result (19). Furthermore, in a retrospective analysis presented at the 2016 ASCO meeting, Landmann et al. analyzed 595 patients who underwent to neoadjuvant treatment from 2010 to 2014. By histological re-evaluation according to the 2013 ASCO/CAP criteria, 46 patients with HER2 equivocal were identified, 31 of them were considered HER2-positive with the previous 2007 ASCO/CAP evaluation and had received trastuzumab therapy. Interestingly, the rate of complete pathological response (pCR) in HER2 equivocal BCs was equivalent to that of HER2-negative BCs (pCR 16\% versus $18 \%$ ), being much lower than that achieved in confirmed HER2-positive BCs (pCR 41\%) (20).

Given these considerations and lacking a clear indication by guidelines, we believe that the Hamletic doubt "to treat or not to treat" HER2 equivocal BCs with anti-HER2 therapy should be addressed for now with no indication for HER2-targeted therapy.

\section{Acknowledgments}

Funding: None.

\section{Footnote}

Provenance and Peer Review: This article was commissioned by the Guest Editors (Gianluca Franceschini, Alejandro Martín Sánchez, Riccardo Masetti) for the series "Update of Current Evidences in Breast Cancer Multidisciplinary Management" published in Translational Cancer Research. The article has undergone external peer review.

Conflicts of Interest: All authors have completed the ICMJE uniform disclosure form (available at http://dx.doi. org/10.21037/tcr.2017.08.34). The series "Update of Current Evidences in Breast Cancer Multidisciplinary Management" was commissioned by the editorial office without any funding or sponsorship. The authors have no other conflicts of interest to declare.

Ethical Statement: The authors are accountable for all aspects of the work in ensuring that questions related to the accuracy or integrity of any part of the work are appropriately investigated and resolved.

Open Access Statement: This is an Open Access article distributed in accordance with the Creative Commons Attribution-NonCommercial-NoDerivs 4.0 International License (CC BY-NC-ND 4.0), which permits the noncommercial replication and distribution of the article with the strict proviso that no changes or edits are made and the original work is properly cited (including links to both the formal publication through the relevant DOI and the license). See: https://creativecommons.org/licenses/by-nc-nd/4.0/.

\section{References}

1. Slamon DJ, Clark GM, Wong SG, et al. Human breast cancer: correlation of relapse and survival with amplification of the HER-2/neu oncogene. Science 1987;235:177-82.

2. Seshadri R, Firgaira FA, Horsfall DJ, et al. Clinical significance of HER-2/neu oncogene amplification in primary breast cancer. The South Australian Breast Cancer Study Group. J Clin Oncol 1993;11:1936-42.

3. Romond EH, Perez EA, Bryant J, et al. Trastuzumab plus adjuvant chemotherapy for operable HER2-positive breast cancer. N Engl J Med 2005;353:1673-84.

4. Piccart-Gebhart MJ, Procter M, Leyland-Jones B, et al. Trastuzumab after adjuvant chemotherapy in HER2positive breast cancer. N Engl J Med 2005;353:1659-72.

5. Slamon D, Eiermann W, Robert N, et al. Adjuvant 
trastuzumab in HER2-positive breast cancer. N Engl J Med 2011;365:1273-83.

6. Goldhirsch A, Gelber RD, Piccart-Gebhart MJ, et al. 2 years versus 1 year of adjuvant trastuzumab for HER2positive breast cancer [HERA]: an open-label, randomised controlled trial. Lancet 2013;382:1021-8.

7. Slamon DJ, Leyland-Jones B, Shak S, et al. Use of chemotherapy plus a mono- clonal antibody against HER2 for meta- static breast cancer that overexpresses HER2. N Engl J Med 2001;344:783-92.

8. Baselga J, Cortés J, Kim SB, et al. Pertuzumab plus trastuzumab plus docetaxel for metastatic breast cancer. $\mathrm{N}$ Engl J Med 2012;366:109-19.

9. Verma S, Miles D, Gianni L, et al. Trastuzumab emtansine for HER2-positive advanced breast cancer. N Engl J Med 2012;367:1783-91.

10. Coates AS, Winer EP, Goldhirsch A, et al. Tailoring therapies-improving the management of early breast cancer: St Gallen International Expert Consensus on the Primary Therapy of Early Breast Cancer 2015. Ann Oncol 2015;26:1533-46.

11. Paik S, Bryant J, Tan-Chiu E, et al. Real-world performance of HER2 testing-National Surgical Adjuvant Breast and Bowel Project experience. J Natl Cancer Inst 2002;94:852-4.

12. Wolff AC, Hammond ME, Schwartz JN, et al. American Society of Clinical Oncology/College of American Pathologists guideline recommendations for human epidermal growth factor receptor 2 test- ing in breast cancer. J Clin Oncol 2007;25:118-45.

13. Moeder CB, Giltnane JM, Harigopal M, et al. Quantitative justification of the change from $10 \%$ to $30 \%$ for human epidermal growth factor receptor 2 scoring in the American Society of Clinical Oncology/ College of American Pathologists guidelines: tumor

Cite this article as: Orlandi A, Arena V. To treat or not to treat: HER2 equivocal is the matter! Transl Cancer Res 2018;7(Suppl 3):S433-S435. doi: 10.21037/tcr.2017.08.34 heterogeneity in breast cancer and its implications for tissue microarray based assessment of outcome. J Clin Oncol 2007;25:5418-25.

14. Wolff AC, Hammond ME, Hicks DG, et al. Recommendations for human epidermal growth factor receptor 2 testing in breast cancer: American Society of Clinical Oncology/College of American Pathologists clinical practice guideline update. J Clin Oncol 2013;31:3997-4013.

15. Fan YS, Casas CE, Peng J, et al. HER2 FISH classification of equivocal HER2 IHC breast cancer with use of the 2013 ASCO/CAP practice guideline Breast Cancer. Res Treat 2016;155:457-62.

16. Long TH, Lawce H, Durum C, et al. The New Equivocal: changes to HER2 FISH results when applying the 2013 ASCO/CAP guidelines. Am J Clin Pathol 2015;144:253-62.

17. Varga Z, Noske A. Impact of Modified 2013 ASCO/CAP Guidelines on HER2 Testing in Breast Cancer. One Year Experience. PLoS One 2015;10:e0140652.

18. Muller KE, Marotti JD, Memoli VA, et al. Impact of the 2013 ASCO/CAP HER2 Guideline Updates at an Academic Medical Center That Performs Primary HER2 FISH Testing: Increase in Equivocal Results and Utility of Reflex Immunohistochemistry. Am J Clin Pathol 2015;144:247-52.

19. Criscitiello C, Bagnardi V, Viale G, et al. HER2 Equivocal Status in Early Breast Cancer Is Not Associated with Higher Risk of Recurrence. Anticancer Res 2016;36:3537-40.

20. Landmann A, Farrugia DJ, Diego E, et al. HER2 equivocal breast cancer and neoadjuvant therapy: Is response similar to HER2-positive or HER2-negative tumors? J Clin Oncol 2016;34:abstr 612. 